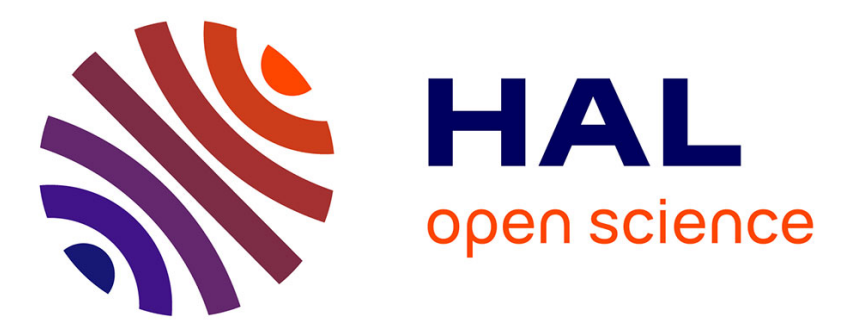

\title{
Needs' elaboration between users, designers and project leaders: Analysis of a design process of a virtual reality-based software
}

Emilie Loup-Escande, Jean-Marie Burkhardt, Olivier Christmann, Simon Richir

\section{To cite this version:}

Emilie Loup-Escande, Jean-Marie Burkhardt, Olivier Christmann, Simon Richir. Needs' elaboration between users, designers and project leaders: Analysis of a design process of a virtual reality-based software. Information and Software Technology, 2014, 56 (8), pp.1049-1061. 10.1016/j.infsof.2014.04.008 . hal-01061182

\section{HAL Id: hal-01061182 \\ https://hal.science/hal-01061182}

Submitted on 5 Sep 2014

HAL is a multi-disciplinary open access archive for the deposit and dissemination of scientific research documents, whether they are published or not. The documents may come from teaching and research institutions in France or abroad, or from public or private research centers.
L'archive ouverte pluridisciplinaire HAL, est destinée au dépôt et à la diffusion de documents scientifiques de niveau recherche, publiés ou non, émanant des établissements d'enseignement et de recherche français ou étrangers, des laboratoires publics ou privés. 


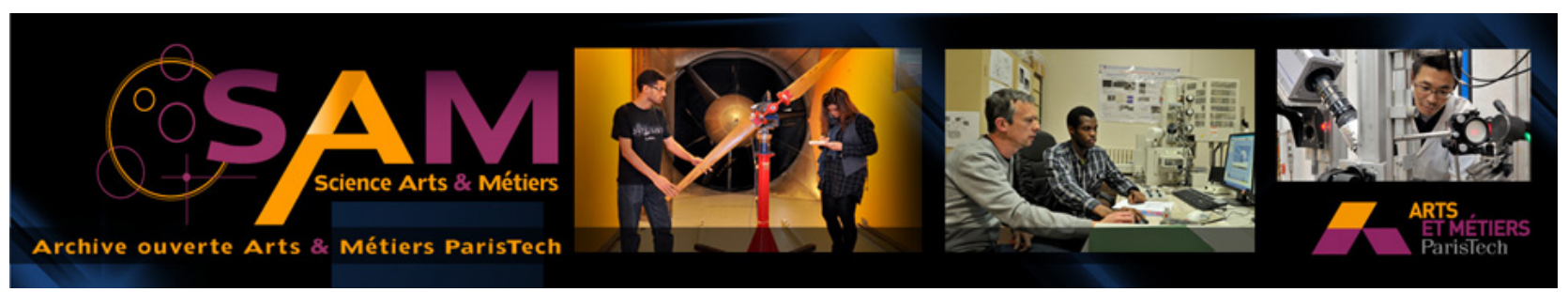

\section{Science Arts \& Métiers (SAM)}

is an open access repository that collects the work of Arts et Métiers ParisTech researchers and makes it freely available over the web where possible.

This is an author-deposited version published in: http://sam.ensam.eu

Handle ID: .http://hdl.handle.net/10985/8463

\section{To cite this version :}

Emilie LOUP-ESCANDE, Jean-Marie BURKHARDT, Olivier CHRISTMANN, Simon RICHIR Needs' elaboration between users, designers and project leaders: Analysis of a design process of a virtual reality-based software - Information and Software Technology - Vol. 56, n8, p.1049-1061 $-2014$ 


\title{
Needs' elaboration between users, designers and project leaders: Analysis of a design process of a virtual reality-based software
}

\author{
Emilie Loup-Escande ${ }^{\mathrm{a}, *}$, Jean-Marie Burkhardt ${ }^{\mathrm{b}, 1}$, Olivier Christmann ${ }^{\mathrm{c}, 2}$, Simon Richir $^{\mathrm{c}, 2}$ \\ ${ }^{a}$ Centre de Recherches en Psychologie, Cognition et Communication, Université Rennes 2, 1 place du recteur Henri Le Moal, 35043 Rennes, France \\ b IFSTTAR, Laboratoire de Psychologie de la Conduite, 25 allée des Marronniers, Satory, 78000 Versailles, France \\ ${ }^{\mathrm{C}}$ LAMPA, Arts et Métiers ParisTech, 2 bd du Ronceray, 49000 Angers, France
}

\begin{abstract}
A B S T R A C T
Context: The participation of users in the design process is recognized as a positive and a necessary element as artifacts suit their needs. Two complementary approaches of users' involvement co-exist: the user-centered design and the participatory design. These approaches involve learning process from users to designers and vice versa. However, there has no research in design of virtual reality (VR)-based software dealing with how the elaboration of needs is actually distributed in time and among users, designers and project leaders, as well as how it is actually supported by tools and methods.

Objective: This paper aims to observe, in a real design project of a virtual reality-based software, how the various stakeholders (users, designers, project leaders) actually participate by sharing and pulling pieces of information from the process of needs elaboration, and how these contributions evolve throughout the decisions made in the course of the project.

Method: Our method, based on the observation of the practices in collective design, allows us to collect and analyze the relationship between each possible action (e.g., elicitation), each stakeholder who initiates these actions (e.g., users) and each phase of the design process (e.g., evaluation phase), and the dynamics of the construction of needs.

Results: Our results detail how the elicited needs are dealt with by designers, users and/or project leaders: (1) we show a strong contribution of users in the design, compared to others stakeholders, (2) among the needs elicited by users, most have been validated by the designers, (3) some elicited needs could have been firstly rejected and finally validated and implemented.

Conclusion: We identify the reasons which justify and explain our results confronting them to the literature. We underline the conditions have been satisfied in our study in order to involve effectively users in the design of emerging technologies.
\end{abstract}

Keywords:

Ergonomics

Design process

Emerging technologies

Needs

\section{Introduction}

The involvement of users is recognized as a positive and a necessary element to support the design of more adapted artefacts [1-6]. This involvement allows to design artefacts that better fit to their actual needs, that are more usable and more accepted [7]. However, several authors (e.g., [8]) have reported that implementing the participation of users has been the source of several difficulties in the field. Barriers have been put forward in literature. A

\footnotetext{
* Corresponding author. Tel./fax: +33223225879.

E-mail addresses: emilie.loup-escande@uhb.fr (E. Loup-Escande), jean-marie. burkhardt@ifsttar.fr (J.-M. Burkhardt), olivier.christmann@ensam.eu (O. Christmann), simon.richir@ensam.eu (S. Richir).

1 Tel.: +33130843933.

2 Tel.: +33243670576.
}

first barrier is that designers do not accept users or only require their integration until the end of the design cycle [9,10]. Indeed, designers are more concerned with the development of the technology than taking users' needs into account [11], because designers think that users are conservative, resistant to change and innovation, and they could be an obstacle to their creativity. This fact leads designers to not accept users or to postpone their integration at the end of the design cycle. A second barrier related to the context of the design of emerging technologies ${ }^{3}$, is that users hardly imagine what needs could be met because they have stereotyped or no knowledge about the technology and they do not know

\footnotetext{
${ }^{3}$ An emerging technology is characterized by a highly innovative concept, few and unclear usages, many limitations that slow down its diffusion and a promise of changing economic and social context [74]. According to these criteria, a virtual reality-based software is an emerging technology.
} 
precisely what can be expected $[12,13]$, because their needs change according to the software evolution and their representations [14] or according to their use of the software [15-19]. These needs, characterized by their nature not yet proven or "unimagined" [20] before or during the implementation, are called "latent" needs [13].

To arouse and take into account all needs including these latent needs in design, two main approaches of user involvement coexist: the user-centered design (UCD) and the participatory design (PD). In UCD, the participation of users refers to users as "providers of information regarding needs and expectations" in the early phase of design [21,22], and as "evaluators of the solution(s) under elaboration" in the subsequent phases [23]. The role of designers is subsequently to "translate" and "select" what they have understood about the situation and the expectations evoked by users or their representatives. PD approach differs in that users are supposed to participate as co-designers [24,25]: they are also involved in design decisions [21,26-29]. The role of designers is to manage the design process (plan the steps, choose the methods and tools). PD implies some forms of democratic [26] or multilateral [27] participation of users together with other stakeholders involved in the design project. Some approaches even propose to support users in implementing their needs themselves through co-creation tools which are adapted to those who are not expert designers [31-33]. These approaches, seen as an extension of participatory design in the field of computer science, are based on environments or languages understandable by users, according to their own level of understanding. End-users do not develop with the designers at the same time, but they develop during the design process and not at the end of the process, to make software patches simply.

These two approaches are complementary in that they position the user in different roles: in UCD, the user is a source of information and an evaluator, while in PD approach, the user is also a codecider. Independently of this role, user participation in design involves the learning process from users to designers and from designers to users $[19,14]$. Indeed, to a certain extent, both UCD and PD emphasize the necessity of facilitating an exchange of knowledge between end-users and designers during the design process, for example through shared representations (e.g. document, mockup, prototype, simulation. . .) and the provision of multiple opportunities for direct contacts and discussions.

The analysis of the roles of users in the design process and of their interactions with designers has been the subject of only a few studies in software design [e.g., 23, 34-36]. Based on their past experiences and readings, Pilemalm et al. argue that one third of a project's resources and duration is focused on the phases of the design process in which users are involved, against two thirds concerning technological phases [34]. The authors suggest that involving users in participatory design leads to a higher number of actions during the phases of identification, refinement, prioritization, evaluation and validation of needs and specifications. They also claim that users improve the design of the new tool: the strong involvement of users allows the result to be more suited to users, even if these authors say nothing about how this suitability is measured. This study does not give us specific elements on the actual contribution of users, compared to designers and others stakeholders in the design, contrary to studies conducted by $[23,35,36]$. Indeed, the study conducted by Barcellini et al. aim at characterizing the links between users (i.e., considered as source of information) and developers in Open Source Software design [35]. To do that, authors investigate the activities and the sharing of knowledge of two contributor profiles through two mailing-lists (useroriented, developer-oriented). The results show that users provide mostly knowledge of their usage and personal experience which were useful to specify usage needs. But their participation does not guarantee that these needs will be taken into account in the actual design.
The study of [36] aims at characterizing the implementation of requirements prioritization by users considered as co-deciders, in the context of the design of a VR-based software. For that, authors analyzed the lists of prioritized functionalities and the functionalities evoked spontaneously by users. The results show that only one functionality noted as "very important" by users was not fully implemented by designers in the final software product, and that several functionalities, non anticipated by designers, have been evoked by users.

The study realized by Fleury et al. is intended to describe the participation of users (i.e., as evaluators) in the design process of a software dedicated to automatically interpret hand-drawn architectural floor plans [23]. Based on experimental studies, the authors show that the software resulting from the user-centered design is more compatible with the users' characteristics than the software resulting from the technological design initially developed in the project.

These studies show that the involvement of users in the design process (UCD or PD) is used to specify and design software products that better reflect the needs and characteristics of the users. However, these studies provide only limited information on what, in the activity of needs elaboration, brings such positive outcomes (e.g., there is little data on the consideration of the needs in the implementation of the software).

To our knowledge, there has been no research in the design of VR-based software dealing with how the elaboration of needs is actually distributed in time and among users, designers and project leaders, as well as how it is actually supported by tools and methods.

The aim of this paper is to observe, in a real design project of a VR-based software, how the various stakeholders (users, designers, project leaders) actually participate by sharing and pulling pieces of information from the process of needs elaboration, and how these contributions evolve throughout the decisions made in the course of the project.

The remainder of the article is organized as follows: in the next section, we describe - based on literature in ergonomics and requirement engineering - the theoretical foundations of the needs elaboration process focusing on activities performed, stakeholders involved and methods used. The concept of "needs" is indeed often poorly defined and different and sometimes contradictory definitions of "needs" coexist in literature. Similarly, from a practical view, the term "needs" is not shared by all stakeholders, including the users themselves. Since the various definitions affect how the requirements are considered in the design process and how the users are involved, it is necessary to clarify the definition and approach used in this research. The third section justifies our methodological choice for the data collection, and we detail the analysis method which considers the need as a unit without taking into account the merging and the restructuration of needs. Then, we describe the results we obtained, regarding the characteristics of the process of needs elaboration that was actually implemented in the project. We detail the relationship between the state of the need (elicited, validated, rejected, implemented), the groups of stakeholders who initiated the actions that led to these states and the phases of the design process (analysis, implementation, evaluation and test). We examine how the elicited needs are dealt with by designers, users and / or project leaders during the design process. In the fourth section, we discuss the reasons that can justify and explain our results, comparing them to literature dealing with design processes that strongly involve users. Finally we conclude.

\section{Related work}

\subsection{Clarifying the notion of needs and requirements in design studies}

As a starting definition, "needs" refer to functions or services associated with a product either prescriptively (i.e., "user 
requirements") or potentially (i.e., "user needs") [37]. Indeed, Pilemalm and al. explain that "The difference between a need and a requirement is sometimes subtle but in other cases substantial. Focusing on requirements at too early a stage leads to a risk of thinking in terms of existing technological and organizational constraints as well as suggesting advanced technological solutions, rather than grasping what is really needed. Further, needs are often more easily acknowledged by the users than requirements, since they relate to their every day context, rather than to an abstract system" [34, p.283]. Although needs have often been considered as existing "expectations" prior to design (i.e., desires or ideas of what could or should be fulfilled with the to-be-designed object), several authors [e.g., 38-41] have insisted on the dynamic nature of needs as a social construction. They acknowledge that needs are not given a priori and evolve through the interactions between designers and users, changing circumstances and mutual learning between users and designers [41]. Being exposed to the artefact or any other shared representation of the state of design can stimulate the evocation of new needs by users as well as by other stakeholders. Since the term "requirement" might be understood restrictively as a static (i.e. no longer evolutive) expected need and because we position ourselves in the social perspective of needs construction described previously, we will therefore use the term "need" in the rest of this paper.

Literature distinguishes further between functional needs (i.e., software can have features like "change the color of the objects"...) and non-functional needs also called "attributes" (i.e., such as performance, security, usability, portability, technical compatibility). Subsequently, implementing a need into an artefact [20] has two complementary aspects: providing the functions that allow users to perform a specific task (i.e., the artefact must contain adequate functionalities), and providing some expected qualities in an optimized way (i.e., the artefact must be light and hand-held, data should be processed in less than $0.5 \mathrm{~s}$. etc.).

Needs can be expressed and thus considered at various degrees of granularity [42,43]. For example the work inspired from Rasmussen's hierarchical levels [44] distinguishes in decreasing order needs expression at the level of goals/roles/services, the level of general needs and the lowest level of detailed needs. The classification of needs used in our study is based on existing classifications $[20,44]$. These classifications are relevant to understand the process of needs elaboration for three reasons. First, the distinction between "function" and "quality" covers the main needs to be taken into account in software design: the functional and hedonic ones. Secondly, the degree of granularity of needs covers the overall design process: both the wider needs (i.e., goals, general) often evoked at the beginning of the design, and the more detailed needs classically enunciated later in the process to refine the design. Thirdly, the combination of the degree of granularity of the need (goal, general and detailed) and its nature (function versus quality) covers all the needs that can be mentioned either by users, by designers or by project leaders.

\subsection{Existing models of needs elaboration processes}

The elaboration of needs in terms of activities, stakeholders involved and methods used has been formalized by several authors.

\subsubsection{Needs elaboration in design process models}

Typically, a design process involving the users is characterized by at least four steps [45]:

- understanding and specifying the context of use;

- specifying the user needs and the other stakeholders' requirements;
- producing design solutions (e.g. scenario, mockup, prototype...);

- evaluating these solutions.

The scope of this kind of design processes is limited as they only take into consideration the elaboration of needs prior to the technical realization, and thus does not cover further needs elaboration during or after the implementation phase.

However, some authors have added another step for the analysis of strategies and problems encountered by users in an actual use situation, after the implementation of the final solution [22]. But user needs identified and expressed at the end of the process are not always taken into account, and even more when technical developments are well advanced. Moreover, we observe that the ISO 9241-210 process and the Bastien and Scapin's process have common steps which can be summarized by three main design phases. Indeed, two steps can be part of the same design phase: e.g. "specification of the context of use" and "specification of the stakeholders' needs" are included in analysis phase. Table 1 describes the correspondence between the four and the five steps of two processes and the three design phases.

The three design phases (i.e., analysis phase, implementation phase, evaluation and test phase) are relevant to formalize the design process which characterizes the study described below, for two reasons. First, we will able to identify the actions of needs elaboration and the contribution of stakeholders at each phase of the process. Secondly, we will analyze the elaboration of needs from the analysis phase to the evaluation phase, not only focusing on the analysis phase as is mostly the case in design process.

\subsubsection{Focus on needs elaboration process}

Several authors have formalized the elaboration of needs [46-48]. The Maguire and Bevan process model [46] consists of four steps. The first step, "information gathering", aims to identify the different needs and requirements of stakeholders, the use context and the tasks of potential users. The second step, "user needs identification", aims to determine the functional and non-functional properties of the future artefact. The third step is the "envisioning and evaluation" during which user feedback can be obtained regarding the system. The fourth step corresponds to the "requirements specification", which is the writing of a document containing the information collected during the previous three steps. Macaulay's process [47] consists of five steps describing how a need goes from a conceptual state to a formalized state in a document. The "concept of the product" is the starting point: it can be either a new idea, or the improvement of an existing product. The second step is the "problem analysis": it is during this stage that the designers identify a set of possible alternatives and new needs. During the third stage called "the feasibility and choice of options", the stakeholders and developers work together to find a compromise on system specifications. The fourth step called "analysis and modeling" is the phase during which each alternative chosen is validated and verified by various stakeholders. This process ends with the writing of the "requirements document" that includes specifications to be implemented at the end.

The Alenljung process [48] corresponds to the last four steps of Macaulay's process: needs elicitation, needs analysis and negotiation, needs documentation and needs validation.

These three processes models have several steps. Each step corresponds to an action of needs construction. At the end of these actions, we observe that a need changes from needs' state $A$ (e.g., elicited) to needs' state B (e.g., validated). Through these processes, we have identified several states of needs: elicitation, validation, rejection and implementation (Table 2).

This classification of needs' states is relevant to understand the process of needs elaboration because it allows the tracing of the 
Table 1

Correspondence between the design phases, and the steps of two process involving users.

\begin{tabular}{lll}
\hline Design phase & Steps of ISO 9241-210's process [45] & Steps of Bastien and Scapin's process [22] \\
\hline Analysis phase & $\begin{array}{l}\text { Specification of the context of use } \\
\text { Specification of the stakeholders' needs } \\
\text { Production of mock-up and prototype }\end{array}$ & Identification of needs \\
Implementation phase & Evaluation of mock-up and prototype & $\begin{array}{l}\text { Production of mock-up and prototype } \\
\text { Production of final solution } \\
\text { Evaluation and test phase }\end{array}$ \\
& & $\begin{array}{l}\text { Evaluation of mock-up and prototype } \\
\text { Evaluation in actual use situation of the final solution }\end{array}$ \\
\hline
\end{tabular}

evolution of a need through each change of state resulting from actions identified in the formalized process of needs elaboration.
This is relevant to integrate several profiles of designers and several profiles of users into our case study in order to identify a wide spectrum of needs.

\subsubsection{Methods and tools used for needs analysis}

Needs analysis can be seen in two ways. First, the needs analysis is the first step of a design process aiming to collect $[22,45]$ or to imagine $[13,54,55]$ the needs, and to select and translate them into specifications for the implementation in the software. Secondly, the needs analysis corresponds to actions of the needs elaboration process that may take place throughout the design, even during the use of software [38-41]. In ergonomics and in requirement engineering, authors have proposed various methods and tools to support these two approaches of needs analysis. Ergonomics suggests: (1) conducting activity analysis based on evaluation of prototypes [53], (2) doing analysis of verbal data produced during meetings involving designers or/and users [56,57]) and (3) using creativity methods [54] (e.g., brainstorming).

Requirements engineering advocates: (1) using prioritization method (e.g., questionnaires with nominal scales, ordinal scales and ratio scales which allow people to assign qualitative or quantitative values to requirements $[2,58,59])$ and (2) formalizing needs in specification document [60].

These methods and tools are complementary in terms of collected data. For example, the verbal data give access to representations of stakeholders involved while behavioral data - which resulted from observation of the use of prototypes or final software - give access to observable behaviors and to potential performance measurements. They are also complementary in terms of the moment they can be used in the design process. For example, creativity methods may help stakeholders to imagine a large number of future or possible needs during the initial design phase, while prioritization methods provide a shorter list of specifications with their priorities which can be used later in the design process.

\subsection{Research objective}

The aim of the study described below is to observe, in a real design project of a VR-based software, how the different stakeholders (users, designers, project leaders) actually participate by sharing and pulling pieces of information from the process of needs elaboration, and how these contributions evolve through the decisions made over the project. For that, we have analyzed - on the basis of the observation of the practices in collective design - the

Table 2

Correspondence between actions of needs construction (related to the process of Maguire and Bevan's, Macaulay and Alenljung), and the states of needs.

\begin{tabular}{lll}
\hline Actions of needs construction & & \\
\hline Maguire and Bevan's process [46] & Macaulay's process [47] & Alenljung's process [48] \\
\hline Information gathering & Concept & Needs elicitation \\
User needs identification & Problem analysis & Needs analysis and negotiation \\
I & Feasibility and choice of options & / Needs validation \\
Requisioning and evaluation & Analysis and modeling & Needs documentation \\
\hline
\end{tabular}


relationship between each possible action (i.e., to elicit, to validate, to reject, to implement), each stakeholder who initiates these actions (i.e., users, designers, project leaders) and each phase of the design process (i.e., the analysis phase, the implementation phase, the evaluation and test phase).

\section{Method}

We conducted a longitudinal study about the participative elaboration of needs in the context of a real design project with emerging technologies. This real project called Appli-Viz'3D took place in a wider project oriented towards the design of a suite of 3D virtual reality software (3D Child, see [61]) for stylists and designers. Data were collected during two years and one half, starting from the initiation of the project to the delivery of its first release.

\subsection{The Appli-Viz'3D case study}

As part of the 3D Child suite, "Appli-Viz'3D" is a virtual realitybased software dedicated to support assessment and visualization of new industrial products in the preliminary phase of design, with the aim of reducing time and cost of the design process. At the end of the project, "Appli-Viz'3D" proposed two virtual environments: a "room" environment (see Fig. 1) and a "car" environment. For more details, see [61].

The "Appli-Viz'3D" project was developed collaboratively by the "Laboratory Arts et Métiers ParisTech of Angers" (LAMPA) and four companies. The project was lead by Company D and involved three Small and Medium Enterprises (companies A, B and $\mathrm{C}$ ). Company $\mathrm{A}$, which has three sites, is a furniture manufacturer with 1050 employees. Company B, which is present in fifteen countries, designs baby products and had 4700 employees in 2006. Company $\mathrm{C}$ is a cabinetmaker specializing in toys and employs nine cabinetmakers.

The 3 SMEs A, B and C were in the same French regional cluster, which included fifty companies in the field of childhood products (e.g., food, toys, furniture). These companies had no special link between them before the project. However, the Laboratory who developed "AppliViz3D" software and conducted the study reported here had already a relationship with the company $A$ in a previous collaborative project.
Developments were carried out in 2 phases, the first during the experiment reported here, with an experienced engineer in computer science and virtual reality and four graduate trainees in virtual reality (acting during four periods of five months on the project duration). The second phase took place after the experiment, and has resulted in the release of a second version of the software (with an engineer experienced in virtual reality). The design project was conducted relying on a design process suitable for the development of applications and virtual reality systems, that is the I2I Method [62] which is based on the I2 method originally proposed by [63].

In order to identify a wide spectrum of needs in this design process, the needs analysis required:

- The implementation of several complementary methods (i.e., prototype evaluation, meetings involving different stakeholders, brainstorming, questionnaires with a prioritization method and specifications report).

- The participation of several profiles of designers and several profiles of users, who are integrated, at the same time, as sources of information, co-deciders and evaluators, and not relegated to only one of these roles.

\subsection{Participants}

Participants were eleven designers from the LAMPA, twentyfive "users" from three companies (A, B, C) and two leaders of the 3D Child project (from Company D). The designers were distributed as follows: five engineers, four stylists, one ergonomist and one "marketer". The experienced engineer, who worked for the Laboratory involved in this project, performed all the developments over the duration of our study. The trainees were directly integrated in the companies A, B and C.

The twenty-five users were: four engineers from Company $A$, six engineers from Company B, four stylists from Company A, three stylists of Company B, one stylist of Company C, four marketers of Company A and three marketers of Company B.

We unfortunately did not access to ages and years of experience for the two project leaders. The remaining participants were aged between 22 and 60 years (average $=37.3$ years; S.D. $=10.2$ years). Their years of vocational experience were between 3 and 37 years ( average $=14.5$ years; S.D. $=11.5$ years ).

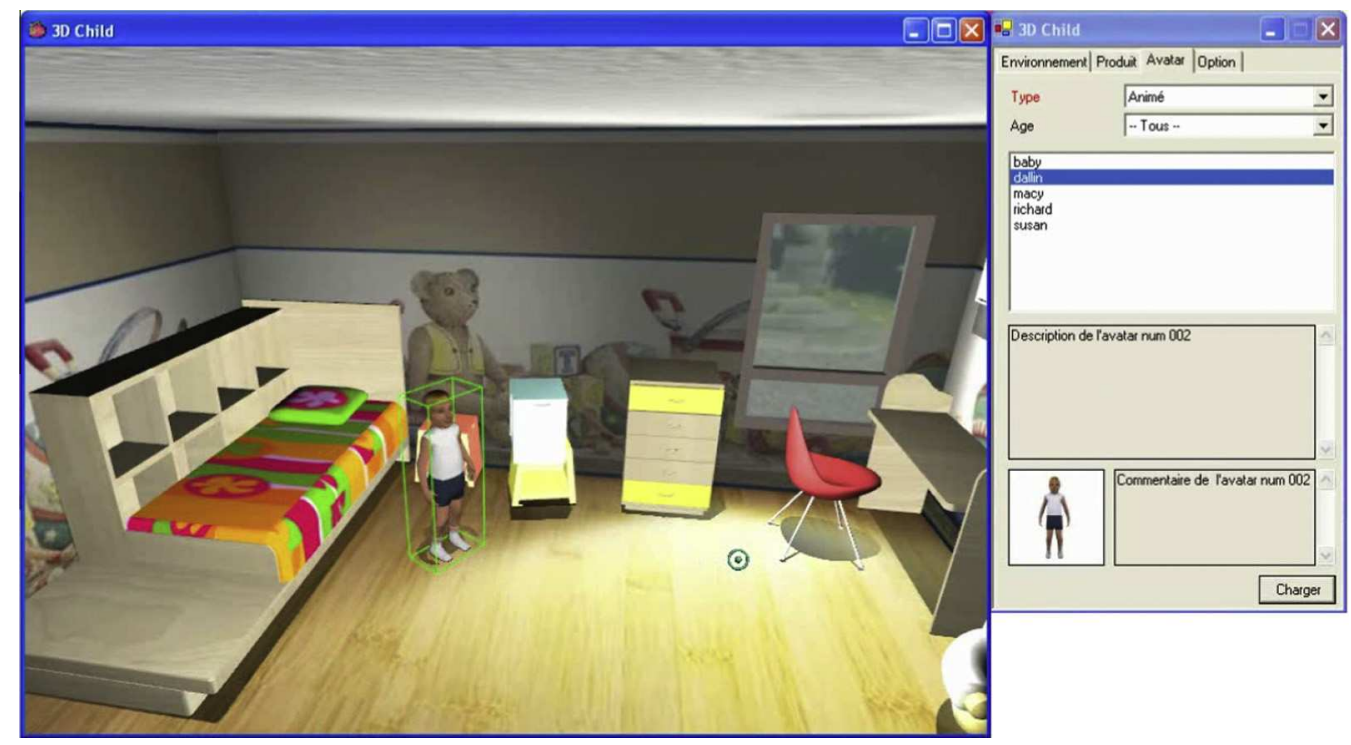

Fig. 1. View of the 3D scene "bedroom" provided by Appli-viz'3D software. 
Most of our users were product designers in their companies (engineers and stylists). Therefore, they are not "end-users" with little experience with the design of artefacts. This can have facilitated the collaboration with designers in the project as well as the elicitation of needs [27].

It should be noticed that the first author of this article has played the role of ergonomist-designer and project manager of the AppliViz'3D, on behalf of the research laboratory in charge of the implementation of the software. The latter author has held the role of marketer-designer (i.e., marketer in the design team of the LAMPA) in the project and has been an active contributor. The other two authors followed the research and contributed to the development of the research methodology and analysis of results. They did not play a part in the process of needs elaboration, but they worked particularly on coding the dynamics of needs elaboration process.

\subsection{Data collection procedure}

The particular position of the first author has facilitated the complete collection of documents generated during the design process between October 1, 2007 and April 1, 2010. This comprises 14 official deliverables dedicated to needs identification and selection (6 specifications reports; 8 presentations of project reviews), 16 internal reports about design meetings, and 3 successive versions of the software artefact.

Moreover, data on users were collected in:

- 7 Verbal transcripts of audio-recorded brainstorming and discussions, particularly on the integration of the tool in practice situation.

- 4 Recordings of use situations of a high-fidelity prototype by "users"; they took place in users' companies.

- 20 Questionnaires which were lists of Appli-Viz'3D functions to be prioritized by users using marks from one to five (one = very important, two =important, three = moderately important, four $=$ unimportant, five $=$ useless ). For more information about questionnaires, you can refer to [51].

The first author attended all project review meetings and inhouse meetings, to follow through the effects of decisions, to observe tests of intermediate representations and consequently modify the specification for the next design solution [64]. This regular presence in the field allowed maintaining a coherent overview of the complete design process. Fig. 2 provides an overview of the design process during the period of the study with activities and produced documents.

The data presented in Fig. 2 have been collected using methods that involved several stakeholders. Table 3 provides a summary of methods used and stakeholders involved for each kind of collected data.

\subsection{Data analysis}

\subsubsection{Extracting needs}

We began by reading through all the documents and other collected verbal material. We looked for any explicit expressions of needs identified, depending on the document, on the basis of formal or verbal markers like "the software will allow", "it would be desirable that", "it should that", "it is necessary that", "I want that", "I need", "I wish that").

144 expressions of needs were identified for this period from October 1, 2007 to April 1, 2010.

3.4.2. Characterizing each need's occurrence in terms of who, when and what decisions were made

Each expression of need content was then categorized according to what content it refers to. We used the following categories:
- expression of expected goals of the software: it represents the purpose of the system that is to say the reason "why" this system must exist (e.g., "the software must help to validate a concept before technical realization"). On the contrary, the following four categories deal with "how" this purpose must be operationalized in the software (i.e., what functions and what attributes);

- expression of a general functionality, that is to say expressions that evoke the functions without details on their integration in the future software in terms of entities concerned and possible precise acts; in this category, functions require further study to be clarified (e.g., the function "change the position of the objects in environment" neither allows to know what objects are concerned (avatars or baby furniture?) nor how objects move (moving an object from point A to point B or performing rotations of objects?);

- expression of a detailed system functionality. This category represents the functions that give suggestions on their integration in the future software; contrary to the previous category, the functionality is enough specified to be implemented in software (e.g., the function "in children room environment, to be able to move and rotate the chair to slide it under the desk" gives enough elements on objects and actions to be implemented);

- general attributes of the software: they evoke the performance, security, usability, portability or technical compatibility without giving details on how it has to be implemented in software; such as "general functionality" category, attributes require further details to be implemented (e.g. the expression "software must be compatible with companies' computer files" refers to portability without detailing the file formats files types or the characteristics of the computers);

- detailed attributes of the software represents the expressions that evoke precisely the performance, security, usability, portability or technical compatibility. These expressions give precise criteria about the implementation of the attributes in software; attributes are sufficiently detailed to be implemented in software (e.g., in the expression "The new-3D objects designed by Company A must be confidential and not accessible to Company $B$. The software must contain, when it starts, a secured access with an identifier (email address) and a password (eight characters) to allow a personalized access to data", the second sentence is here precise because it details the implementation of security properties in software).

This categorization of needs was done manually. The resulting coding has been controlled and validated by a senior designer expert in needs analysis.

Each need was also characterized by the source it was extracted from (e.g. document $\mathrm{X}$, meeting $\mathrm{Y}$, etc.), the associated date of appearance and who mentioned it. Furthermore, each time the same need was encountered in our material at different time, we associated in our data the need and the decision, if a new decision was made. The decisions were coded as follows:

- elicited when the need was only evoked without any decision regarding its consideration or not to be implemented in the project;

- validated, when the need was explicitly accepted as part of the design by at least one person which can be a user, a designer or a project leader;

- rejected, when the need was explicitly rejected;

- implemented, when the need was actually implemented by a designer;

- in progress: we coded this later case when the need had been expressed but neither rejected nor validated at the April 1, 2010. 


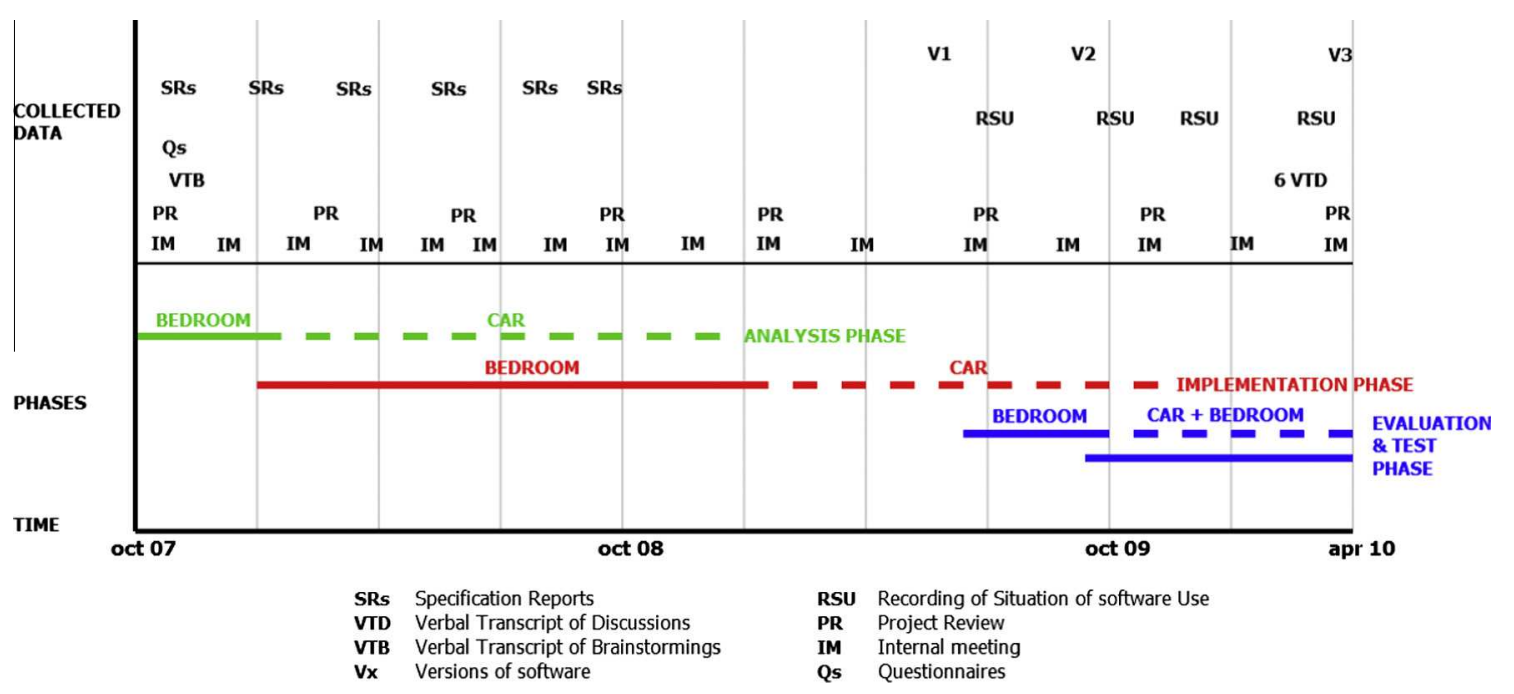

Fig. 2. Formalization of the design process.

Table 3

Methods and stakeholders associated to each kind of collected data.

\begin{tabular}{|c|c|c|}
\hline Collected data & Methods & Stakeholders \\
\hline The Verbal Transcript of Discussions (VTD) & Meeting & $\begin{array}{l}\text { Designers } \\
\text { Users }\end{array}$ \\
\hline The Verbal Transcript of Brainstorming (VTB) & Brainstorming & $\begin{array}{l}\text { Designers } \\
\text { Users }\end{array}$ \\
\hline The Recording of Situation of Use (RSU) & Evaluation of high-fidelity prototype & $\begin{array}{l}\text { Designers } \\
\text { Users }\end{array}$ \\
\hline The analysis of priority level of functionalities proven by Questionnaires (Qs) & $\begin{array}{l}\text { Questionnaire } \\
\text { Prioritization method }\end{array}$ & $\begin{array}{l}\text { Designers } \\
\text { Users }\end{array}$ \\
\hline Internal Meetings (IM) & Meeting & Designers \\
\hline Specification Reports (SRs) & Formalization of needs in specification report & $\begin{array}{l}\text { Designers } \\
\text { Users } \\
\text { Project leaders }\end{array}$ \\
\hline The Versions of Software (Vx) & Programming & $\begin{array}{l}\text { Designers } \\
\text { Users }\end{array}$ \\
\hline Project Reviews (PR) & Meeting supported by demo of prototype & $\begin{array}{l}\text { Designers } \\
\text { Users } \\
\text { Project leaders }\end{array}$ \\
\hline
\end{tabular}

The results of the actions of construction of needs are states of needs in the words of requirements engineering: elicited, validated, rejected and implemented.

An example of collected need was "3D Avatars should be able to adopt ergonomics positions". This need was elicited by one marketer of LAMPA during the meeting held in October 24, 2007, since it has been extracted from the corresponding transcription. One month after (November 2007) a questionnaire was given to users (engineers, stylists and marketers of Company $A$, engineers and marketers belonging to Company $\mathrm{B}$ and stylist of Company $\mathrm{C}$ ) and they ranked this need as a design priority. Later on, this need was officially rejected by the engineers of LAMPA during the project meeting held in June 20, 2008.

The example of coding associated to this need is given in Table 4.

\subsubsection{Coding the dynamics of needs elaboration process}

In order to characterize the dynamics of needs elaboration, we split the process up into three phases. Several alternatives could have been used to specify subsequent phases in the process. For example, we could have cut arbitrarily the duration into three periods of an equivalent duration. However, there are many models that describe the design process by defining some phases, from a procedural point of view [65] or according to the level of progression of the project [44]. Thus, based on the main models of each product design disciplines involved in the "3D Child" project such as marketing [66], stylism [67], engineering [62] and ergonomics [22], we describe the design process according to these three following phases (see Section 2.2.1):

- the "analysis phase" corresponds to the clarification of objectives, stages of the project [68], the characterization of the current situation (modeling of the design process currently spread out in the three partner companies) and some needs [69];

- the implementation and technical realization phase of prototypes ("implementation phase");

- the "evaluation and test phase" corresponds to the insertion and tracking of the artefact in its use situations in which latent needs arose [69].

The objective criteria to determine the beginning and the end of each phase depend on the project schedule. The "analysis phase" includes everything that happened between the starting of the project and the specifications delivery. For the implementation and technical realization phase, we consider all actions that took place between the beginning of the implementation of functionalities and attributes contained in the specifications report and the production of the first high-fidelity prototype. The "evaluation and 
Table 4

Extract of the coding table of needs

\begin{tabular}{|c|c|c|c|}
\hline Date & Source & Who & Action \\
\hline \multicolumn{4}{|c|}{ Need \#1: "To give ergonomic postures to 3D models" } \\
\hline October 24, 2007 & Meeting & Marketer LAMPA & Elicited \\
\hline November 8 and 26, 2007 & Questionnaire & Engineer A + Stylist A + Marketer A + Engineer B + Marketer B + Stylist C & Validated \\
\hline June 20, 2008 & Meeting & Engineer LAMPA & Rejected \\
\hline
\end{tabular}

test phase" includes everything which was produced when the first high-fidelity prototype was made available to the users in companies.

The phases which took place between October 1, 2007 and January 1, 2008 for the "bedroom" module and between October 1 , 2007 and December 1, 2008 for the "car" module, correspond to the analysis phase. We considered that the actions that took place between February 1, 2008 and May 1, 2009 for the "bedroom" module, and between January 1, 2009 and November 9, 2009 for the "car" module, correspond to the implementation phase. The actions which took place between June 1, 2009 and April 1, 2010 for the "bedroom" module, and between September 14, 2009 and April 1, 2010 for the "car" module, are associated with the evaluation and test phase.

To investigate the contribution of stakeholders to actions of construction of needs, we considered three categories: designers, users and project leaders. This categorization allows us to study the real role and contribution of users in the design of innovative artefacts, in interaction with designers and project leaders. Concerning the application of this stakeholders' categorization, the LAMPA's persons were designers, professionals of companies A, B and C were users and finally professionals of the organization who lead the Appli-Viz'3D project were the project leaders.

3.4.4. Decomposition of the needs into basic units of action related to their construction

The 144 needs were then split up into basic units of action. A basic unit corresponds to one of four actions related to the construction (elicitation, validation, rejection, implementation) associated to a specific need (e.g., "allowing a 3D character to have an action on an object") and to an identified participant (e.g., B engineer, B marketer, A stylist). Thus, to the same action (e.g., to draw the need "allowing a 3D character to have an action on an object") could correspond three action-units if this need was elicited threefold (by B engineer, B marketer and A stylist). Moreover, if the stylist had elicited two other needs, for example "to develop a desktop environment" and "to have an avatar of a 4-years-old child in the database", we counted three acts for the A stylist. In total, this coding resulted in 600 actions-units.

\subsubsection{Analyzing actions and contributors to the dynamics of the construction of needs}

The dynamics of the construction of needs can be analyzed by looking at how actions are ordered at different stages. In others words, dynamics represent sequences of actions associated to needs and falling within a specific temporality related to the 3 phases of the needs elaboration. These dynamics of the construction of needs involve the needs elicited by the designers, users and / or project leaders during the whole design process. To identify these dynamics of construction of needs, we proposed two ways of analyzing the sequences:

- the succession of states associated to each needs: e.g. "needs elicited and rejected";

- the stakeholders role associated with each state needs: e.g. "needs elicited by users and validated by designers".

\subsection{Statistical analysis}

Mono and bivariate descriptive statistical analyses were carried out. Since our data were essentially categories, bivariate analyses were based on contingency tables analyzed with two main indicators. Cramer's $V^{2}$ estimates the magnitude of the association between two categorical variables $[70,71]$. Cramer's $V^{2}$ is calculated by dividing the $\mathrm{phi}^{2}$ by the $\mathrm{phi}^{2}$ max. $\mathrm{Phi}^{2}$ is the average deviation in the table and $\mathrm{Phi}^{2}$ max is the smallest dimension in the table minus 1 . Cramer's $V^{2}$ lies between 0 and 1 . The association is conventionally considered as strong when $V^{2}>.16$ and as weak when $V^{2}<.04$ [30].

Relative deviations (RD) measure the association between modalities of two nominal variables [72], e.g. needs elicitation by designers in the analysis phase. They are calculated on the basis of a comparison between observed and expected frequencies (i.e. those that would have been obtained if there was no association between the two variables), according to the following formula: $\mathrm{RD}=$ (observed data - theoretical data)/theoretical data. There is attraction when the $\mathrm{RD}$ is positive, and repulsion when it is negative. By convention, we retain only RD with absolute terms $>.25$.

These statistical analysis have been used in different studies which are based on nominal variables $[11,73]$.

\section{Results}

\subsection{Co-elaboration of needs: patterns and contributors}

4.1.1. Simple patterns of co-elaboration dominate: after being elicited, needs were generally either validated or rejected

Observed sequences of (co-)elaboration of the 144 needs are given in Table 5. It highlights that elicited needs were in majority validated ( $56 \%$ of the 144 needs) at the end of the observed period, while $14 \%$ were rejected. It is interesting to note that $20 \%$ of the elicited needs have not been dealt with (i.e. neither rejected nor formally validated) by the project participants at the time we ended our observation. These three simple patterns of needs elaboration logically dominate, as they represent the sequence supported by design methods.

However $10 \%$ of the elicited needs followed more complex patterns. Indeed, $6 \%$ of needs were validated twice, $3 \%$ were at first validated and then rejected and $1 \%$ of the elicited needs were at first rejected and finally validated. This latter type of sequence is typically linked to the resolution of technological problems that the designer thought difficult to achieve before to do it (e.g., "being able to slide a chair under a desk").

\subsubsection{Design decisions seem to partially depend on the profile of stakeholders that initiated the need}

We have compared the sequences and issues of needs depending on the category of stakeholders who were the initiators of these states (Table 6). The data showed that the majority of needs have been elicited by users (98/144; i.e. $68 \%$ ). Among these 98 user-elicited needs, 29 elicited needs evoked during meeting related to the analysis phase have never been dealt with (i.e. $30 \%$ ), 48 were ultimately validated (i.e. $49 \%$ ) and 21 were ultimately rejected (i.e. $21 \%$ ). Only 40 out of the 144 needs were elicited by the designers 
Table 5

Sequences of statements of needs: description, frequency and proportion.

\begin{tabular}{lcr}
\hline Observed patterns of needs co-elaboration & Frequency & $\%$ \\
\hline Elicited and validated & 81 & 56 \\
Elicited and rejected & 19 & 14 \\
Elicited and not dealt with & 29 & 20 \\
Elicited, validated and rejected & 5 & 3 \\
Elicited, rejected and validated & 2 & 1 \\
Elicited, validated and validated again & 8 & 6 \\
All & 144 & 100 \\
\hline
\end{tabular}

\section{Table 6}

Issues regarding the process of need co-elaboration as a function of the profile of its initiator.

\begin{tabular}{lllll}
\hline Need elicited by & Not dealt with & Validated & Rejected & Total \\
\hline Users & $29(30 \%)$ & $48(49 \%)$ & $21(21 \%)$ & $98(100 \%)$ \\
Designers & 0 & $37(92 \%)$ & $03(8 \%)$ & $40(100 \%)$ \\
Users and designers & 0 & $05(100 \%)$ & 0 & $05(100 \%)$ \\
Users and & 0 & 01 & 0 & 01 \\
Project leaders & & & & \\
\hline
\end{tabular}

(i.e. 28\%). Among these designer-elicited needs, 37 were ultimately validated and implemented (i.e. 92\%) and only 3 were ultimately rejected (i.e. 8\%). Finally, 5 out of the 144 needs (i.e. 3\%) were elicited by the designers and users, and only one (i.e. $1 \%$ ) has been proposed by users and project leaders. Two reasons can explain these results: the first one is that the designers carry more weight with deciding to implement or not the need in the artefact; the second reason is that end-users express expectations which appear broader and less well-considered in terms of feasibility, than the designers who express only needs they know they will be able to implement. Thus, needs appear to be selected (i.e. validated or implemented) differently depending on the profile of stakeholders that had initiated them.

Table 7 describes the detailed sequences of co-elaboration of needs initiated by the various profiles of the project participants: we observed that some needs were elicited, rejected and/or validated by many people before their implementation. For example, on 91 needs implemented (i.e., in fine validated with regards to the 144 elicited needs), this table shows that:

- 7\% have been elicited by two profiles of stakeholders: 1 need elicited by users and project leaders and 5 needs elicited by users and designers;

- 33\% have been validated by two or three profiles of stakeholders: 17 needs validated by two profiles (e.g., needs elicited by users and validated by designers and projects leaders) and 13 needs validated by three profiles (e.g., needs elicited by designers and validated by designers, users and project leaders).

Moreover, we observe that making decisions about the needs are different depending on the stakeholders who elicited them. For example, Table 7 shows that the needs elicited by users are mainly not dealt with $(29 / 144$, i.e. $20 \%)$, validated by designers (25/144, i.e. $17 \%)$, and rejected by designers, users and project leaders $(12 / 144$, i.e. $8 \%)$, while those elicited by designers are mainly validated by designers (12/144, i.e. $8 \%$ ) and by users (10/ 144 , i.e. $7 \%$ ).

\subsection{Analyzing contribution at the action level}

\subsubsection{The type of contribution differs depending on the profile of stakeholders}

The further coding of the 144 collected needs resulted in 600 actions-units representing a specific states of the needs resulting from a specific action (elicitation, validation, rejection etc.) associated to one need at a specific moment. Table 8 shows the frequencies of the various states of needs as a function of contributor profiles whatever the phase of the project.

Two categories of action units corresponding to an act of need elaboration were most represented: validation acts $(251 / 600$, i.e. $42 \%)$ and elicitation acts (181/600, i.e. $30 \%)$. The high number of validation acts can be explained by the fact that several contributors were involved (e.g., as described in Table 7, some needs elicited by designers were validated by designers, users and project leaders). Beyond these two categories, $79 / 600$ acts (i.e. 13\%) were implementation acts at the moment we collected the data, and $89 / 600$ acts (i.e. $15 \%$ ) were rejection acts. Looking at the contribution of our three stakeholders' profiles, we observe that users have more participated as they represented more than half of the actions-units (323/600, i.e. $54 \%)$. They are followed by designers (244/600, i.e. $41 \%$ ) and by project leaders (33/600, i.e. 5\%).

There was an intermediate association between the profile of stakeholders and the actions of needs elaboration (Cramer's $\left.V^{2}=0.14\right) . \mathrm{RD}^{4}$ reveal a noticeable positive attraction between users and elicitation acts $(\mathrm{RD}=+0.28)$. Inversely, there is a repulsion between elicitation and both designers group $(\mathrm{RD}=-0.25)$ and project leaders $(\mathrm{RD}=-0.90)$.

Validation of needs is characterized by a strong attraction with project leaders group $(\mathrm{RD}=+0.45)$, as well as by a repulsion with designers group is observed $(\mathrm{RD}=-0.29$ ).

Project leaders group exhibits a strong attraction with rejection acts $(\mathrm{RD}=+1.45)$. Implementation acts are strongly attracted by the designers group $(\mathrm{RD}=+1.46)$, and inversely repulsed by users group $(\mathrm{RD}=-1.00)$ and project leaders group $(\mathrm{RD}=-1.00)$.

The main attractions are summarized in Fig. 3.

\subsubsection{Number and type of actions related to needs differ depending on} the design phase

The distribution of the 600 actions-units across the three design phases (Table 9) shows that the implementation phase is the most important phase in the process of needs co-elaboration. Indeed, implementation phase represents more than the half of the collected actions-units (306/600, i.e. 51\%). Lowest frequencies of action-units are found for the "analysis phase" (211/600, i.e. $35 \%)$ and especially for the "evaluation and test phase" (83/600, i.e. $14 \%)$.

There is an intermediate global association between the two variables "actions of needs elaboration" and "phase of design" (Cramer's $V^{2}=0.11$ ). Logically, the analysis of RD shows that the "analysis phase" is characterized by a strong attraction with elicitation of needs $(R D=+0.60)$. A repulsion is observed with the rejection acts $(R D=-0.81)$ and implementation acts $(R D=-0.86)$. The "evaluation and test phase" is similarly characterized by a strong attraction with the elicitation acts $(\mathrm{RD}=+0.40)$. Inversely, a repulsion is observed with the rejection acts $(\mathrm{RD}=-0.51)$. The "implementation phase" is characterized by a strong attraction with the rejection acts $(R D=+0.69)$ and implementation acts $(R D=+0.61)$. Inversely, repulsions are observed with the elicitation acts $(\mathrm{RD}=-0.52)$. The main attractions are summarized in Fig. 4.

\subsubsection{Participation in the design phases differs according to the profile of stakeholders}

The distribution of the 600 actions-units across the three design phases (Table 10) shows that the implementation phase is the most important phase in terms of actions-units (306/600, i.e. $51 \%)$, followed by the "analysis phase" (211/600, i.e. $35 \%)$ and by

\footnotetext{
${ }^{4}$ As stated before, we only report following on associations that exhibited a RD value in absolute terms $>25$.
} 
Table 7

Sequences of statements of needs initiated by project participants: description, frequency and proportion.

\begin{tabular}{|c|c|c|c|c|}
\hline \multirow{2}{*}{$\begin{array}{l}\text { States of needs } \\
\text { Needs elicited and validated }\end{array}$} & \multicolumn{2}{|c|}{ Sequence of statements of needs initiated by project participants } & \multirow{2}{*}{$\frac{\text { Freq. }}{2}$} & \multirow{2}{*}{$\frac{\%}{1}$} \\
\hline & Needs elicited by users and validated & Needs elicited by users and validated by designers and users & & \\
\hline & & $\begin{array}{l}\text { Needs elicited by users and validated by designers, users and } \\
\text { project leaders }\end{array}$ & 7 & 5 \\
\hline & & Needs elicited by users and validated by designers & 25 & 17 \\
\hline & & $\begin{array}{l}\text { Needs elicited by users and validated by designers and projects } \\
\text { leaders }\end{array}$ & 5 & 3 \\
\hline & & Needs elicited by users and validated by users & 5 & 3 \\
\hline & Needs elicited by designers and validated & $\begin{array}{l}\text { Needs elicited by designers and validated by designers and } \\
\text { users }\end{array}$ & 1 & 1 \\
\hline & & $\begin{array}{l}\text { Needs elicited by designers and validated by designers, users } \\
\text { and project leaders }\end{array}$ & 6 & 4 \\
\hline & & Needs elicited by designers and validated by designers & 12 & 8 \\
\hline & & $\begin{array}{l}\text { Needs elicited by designers and validated by users and project } \\
\text { leaders }\end{array}$ & 1 & 1 \\
\hline & & Needs elicited by designers and validated by users & 10 & 7 \\
\hline & & Needs elicited by designers and validated by project leaders & 1 & 1 \\
\hline & $\begin{array}{l}\text { Needs elicited by users and project leaders, and } \\
\text { validated }\end{array}$ & $\begin{array}{l}\text { Needs elicited by users and project leaders, and validated by } \\
\text { designers }\end{array}$ & 1 & 1 \\
\hline & $\begin{array}{l}\text { Needs elicited by users and designers, and } \\
\text { validated }\end{array}$ & $\begin{array}{l}\text { Needs elicited by users and designers, and validated by } \\
\text { designers }\end{array}$ & 5 & 3 \\
\hline \multirow[t]{2}{*}{ Needs elicited and rejected } & Needs elicited by users and rejected & Needs elicited by users and rejected by designers & 7 & 5 \\
\hline & & $\begin{array}{l}\text { Needs elicited by users and rejected by designers, users and } \\
\text { project leaders }\end{array}$ & 12 & 8 \\
\hline \multirow[t]{3}{*}{ Needs elicited, validated and rejected } & Needs elicited by users, validated and rejected & $\begin{array}{l}\text { Needs elicited by users, validated by users and rejected by } \\
\text { designers }\end{array}$ & 1 & 1 \\
\hline & & $\begin{array}{l}\text { Needs elicited by users, validated by designers and users and } \\
\text { rejected by users }\end{array}$ & 1 & 1 \\
\hline & $\begin{array}{l}\text { Needs elicited by designers, validated and } \\
\text { rejected }\end{array}$ & $\begin{array}{l}\text { Needs elicited by designers, validated by users and rejected by } \\
\text { designers }\end{array}$ & 3 & 2 \\
\hline \multirow[t]{2}{*}{ Needs elicited, rejected and validated } & Needs elicited by users, rejected and validated & $\begin{array}{l}\text { Needs elicited by users, rejected by designers and users, and } \\
\text { validated by users }\end{array}$ & 1 & 1 \\
\hline & & Needs elicited by users, rejected and validated by designers & 1 & 1 \\
\hline \multirow[t]{4}{*}{$\begin{array}{l}\text { Needs elicited, validated firstly and } \\
\text { validated secondly }\end{array}$} & $\begin{array}{l}\text { Needs elicited by users, validated firstly and } \\
\text { validated secondly }\end{array}$ & $\begin{array}{l}\text { Needs elicited by users, validated firstly by users and validated } \\
\text { secondly by designers }\end{array}$ & 1 & 1 \\
\hline & & $\begin{array}{l}\text { Needs elicited by users, validated firstly by designers and } \\
\text { validated secondly by users }\end{array}$ & 1 & 1 \\
\hline & $\begin{array}{l}\text { Needs elicited by designers, validated firstly } \\
\text { and validated secondly }\end{array}$ & $\begin{array}{l}\text { Needs elicited by designers, validated firstly by users and } \\
\text { validated secondly by designers }\end{array}$ & 5 & 3 \\
\hline & & $\begin{array}{l}\text { Needs elicited by designers, validated firstly by designers and } \\
\text { validated secondly by users }\end{array}$ & 1 & 1 \\
\hline Needs elicited and not dealt with & Needs elicited by users and not dealt with & - & 29 & 20 \\
\hline
\end{tabular}

Table 8

Action related to needs' elaboration versus kind of stakeholders: frequencies.

\begin{tabular}{lcccr}
\hline & Designers & Users & Project leaders & \multicolumn{1}{c}{ All } \\
\hline Elicitation & 55 & 125 & 1 & 181 \\
Validation & 72 & 159 & 20 & 251 \\
Rejection & 38 & 39 & 12 & 89 \\
Implementation & 79 & 0 & 0 & 79 \\
All & 244 & 323 & 33 & 600 \\
\hline
\end{tabular}

the "evaluation and test phase" (83/600, i.e. $14 \%)$. We also observe that users have produced more actions-units (323/600, i.e. 54\%),

\begin{tabular}{|lll|}
\hline Elicitation & $\longrightarrow$ & Users \\
Validation & $\longrightarrow$ & \\
Rejection & $\longrightarrow$ & Project leaders \\
Implementation & & Designers \\
\hline
\end{tabular}

Fig. 3. Main attractions based on $\mathrm{RD}$ values between action related to needs' elaboration and profile of stakeholders.
Table 9

Action related to needs' elaboration versus phases of design: frequencies.

\begin{tabular}{lrrlr}
\hline & Analysis & Implementation & Evaluation and test & All \\
\hline Elicitation & 102 & 44 & 35 & 181 \\
Validation & 99 & 120 & 32 & 251 \\
Rejection & 6 & 77 & 6 & 89 \\
Implementation & 4 & 65 & 10 & 79 \\
All & 211 & 306 & 83 & 600 \\
\hline
\end{tabular}

followed by designers $(244 / 600$, i.e. $41 \%)$ and by project leaders $(33 / 600$, i.e. $5 \%)$.

There is an intermediate global association between the variables "profile of stakeholders" and "phase of design" (Cramer's $V^{2}=0.06$ ). The analysis of noticeable RD shows that the "analysis phase" is characterized by a strong attraction with users group $(\mathrm{RD}=+0.31)$, and inversely a repulsion with designer group $(\mathrm{RD}=-0.31)$ and even more with project leaders group $(\mathrm{RD}=-0.74)$. The "implementation phase" in characterized by a strong attraction with project leaders group $(\mathrm{RD}=+0.78)$ and with designers group $(\mathrm{RD}=+0.29)$, while users contribute proportionally less $(\mathrm{RD}=-0.30)$.

We can observe that users participate strongly to the "evaluation and test phase" $(\mathrm{RD}=+0.32)$ and designers participate lightly $(\mathrm{RD}=-0.29)$, and the project leaders group does not contribute at this phase $(\mathrm{RD}=-0.1)$. 


\begin{tabular}{|ll|} 
Elicitation & $\longrightarrow$ Analysis \\
Validation & $\bullet$ Evaluation and test \\
Implemention & Implementation phase \\
\hline
\end{tabular}

Fig. 4. Main attractions between action related to needs' elaboration and phase of design.

Table 10

Profile of stakeholders versus phases of design: frequencies.

\begin{tabular}{lcccc}
\hline & Analysis & Implementation & Evaluation and test & All \\
\hline Designers & 59 & 161 & 24 & 244 \\
Users & 149 & 115 & 59 & 323 \\
Project leaders & 3 & 30 & 0 & 33 \\
All & 211 & 306 & 83 & 600 \\
\hline
\end{tabular}

\begin{tabular}{|ll|}
\hline Users & Analysis \\
Designers & Implementation \\
Project leaders & Evaluation and test \\
\hline
\end{tabular}

Fig. 5. Main attractions between kind of stakeholders and phase of design.

The main attractions are summarized in Fig. 5.

\section{Discussion}

Our study analyzes the actual participation of users in needs elaboration in a real project in the context of the design of VR-based software, by looking on types, phases and contributive actions of the various profiles of stakeholders that participated. We also clarify the dynamics of needs elaboration.

Contrary to what was stated by several authors [8-10], actively involving the end-users in the design of emerging technologies is possible. Indeed, our results show particularly a strong contribution of users to the design of VR-based software, so that users have produced more actions than designers and project leaders. One possible explanation for this result is that designers and project leaders have given the user both a role of "source of information", "co-decider" and "evaluator". These three roles have allowed users to perform actions of elicitation and rejection/validation, throughout the design process (i.e., during the analysis, implementation and evaluation phases), while the scope of action of designers and project leaders was only the decision making process.

Users' contribution concerns mainly the actions of needs' elicitation during the phases of analysis and evaluation/test, compared to the actions of decisions like rejection and validation of needs. This observation converges with studies described in literature which suggest the strong involvement of users in the expression of needs or the imagination of solutions [29]. In our study, this can be explained by the choice of the most appropriate methods for the needs' enunciation compared to those proposed for the needs' selection. Indeed, the method chosen for the prioritization, selection and rejection of functionalities was less familiar to the users, compared to the methods which allowed them to verbalize and elicit their needs during the analysis and evaluation phases (i.e., meetings, brainstorming, evaluation of prototypes). Among the needs elicited by users, most have been validated by the designers. We think that needs identified by users were not rejected in large numbers by designers, because users were involved in meetings with designers and projects leaders, promoting a "multilateral participation" of all the participants in the project [27]. Then, this probably allowed a mutual learning between users, designers and project leaders during the meetings facilitating the exchange and the sharing of knowledge between them [41]. Indeed, the designers were able to exchange with users and then understand their needs, the benefits of intended functionalities for the end-users, and the activity for which the artefact had to be designed. In the same way, the users can understand the requirements of project leaders and the constraints of designers, and then evoke needs integrating them.

However, users interpret the requirements of project leaders and the constraints of designers based on their own level of knowledge and understanding. Thus, among the rejected needs, the needs elicited by users were more often rejected than the needs elicited by designers. Some needs were rejected by the designers because they were judged difficult or impossible to implement because of technical feasibility and deadlines. For example, the need elicited by users "customizing the product itself directly with Appli-Viz'3D" was rejected by designers because it was very difficult to finish on time without exceeding the budget. Inversely, the functionality "adopting different points of view: child, external, front or behind the car" proposed by designers was validated by users; designers who had elicited this functionality knew it was technically possible.

$30 \%$ of needs elicited by users were not dealt with (i.e. neither validated nor rejected) by the designers. Two reasons may explain these results. The first is the elusive nature of the elicited needs that typically were vague and ambiguous (e.g., "automatic update of new trends", "introduction of the seasons in software"). The second reason concerns the difficulty to take into account new needs during the end of the technical realization (e.g., "create several types of rooms, such as a room with two windows and two doors, in addition to the one implemented that includes a window and a door"). The designers did not reject these needs because they were likely to be developed in a second version of the artefact. In addition, they were not able to confirm these needs because if they had validated them, then they would have needed to have implemented them. This was impossible with regards to the deadline.

Another interesting result was that some elicited needs could at first be rejected but validated and implemented afterwards. Three reasons can explain this observation. Firstly, the project leaders imposed the development of the functionality on designers because they believed it too risky to not implement it (e.g., to sell the software) [50]. Secondly, the designers measured the importance of the functionality for the users and redefined their priorities [41]. Thirdly, the designers become progressively more knowledgeable in programming during the project, and thus were able to develop features they thought initially impossible to technically achieve (e.g., "being able to slide a chair under a desk").

\section{Conclusion}

The aim of this paper was to report, in the context of a real design project of a VR-based software, on how the various stakeholders (users, designers, project leaders) actually participate by sharing and pulling pieces of information from the process of needs elaboration, and how these contributions evolve throughout the decisions made over the course of the project.

For that, we collected and analyzed the links between each possible actions related to needs elaboration (i.e., elicitation, validation, rejection, implementation), the profile of the stakeholders profile who initiate these actions (i.e., users, designers, project leaders) and each phase of the design process (i.e., analysis phase, implementation phase, evaluation and test phase), and the 
dynamics of the needs elaboration. Our study provides empirical elements of understanding on how the expressed needs are dealt with by designers, users and/or project leaders throughout the phases of the design process of emerging technologies like virtual reality. The participation in the design phases is different according to the profile of each stakeholder: users are more active during the phases of analysis and evaluation, while designers and projects leaders are mainly active during the implementation phase. Concerning the evolution of needs construction, simple patterns dominate (i.e., needs were generally validated or rejected) compared to the needs not dealt with and the most complex patterns of actions (e.g., needs were rejected and the validated). Moreover, among the needs elicited by users, most have been validated by the designers.

Besides having characterized this process of needs elaboration, our study suggests that actively involving users in the design of emerging technologies is possible and effective (i.e., designers will actually implement the needs elicited by users in the software) if four conditions are satisfied. The first condition is to involve users as "sources of information", "co-deciders" AND "evaluators", and not through only one of these roles:

- the user as "source of information" would only have an activity of needs elicitation during the analysis phase;

- the user as "co-decider" would have an activity of decision making among a list of needs or functionalities, and if this list is incomplete then several important needs would never have been implemented in software;

- the user as "evaluator" would have an activity of judge at the end of the design leaving little chance that designers incorporate his remarks.

The users will successively hold these roles at the different stages of the design process.

The second condition, necessary for the implementation of the first condition, is to choose methods that promote elicitation (e.g., brainstorming), prioritization (e.g., prioritization's questionnaire) and evaluation as early as possible in the design process (e.g., prototype evaluation) by the users.

The third condition is to promote exchanges and confrontations of points of view between the users, designers and project leaders throughout the design through meetings, which may be based on specifications documents and versions of software (i.e., prototypes).

The fourth condition is to involve several profiles of designers and users: having engineers, stylists and ergonomists has allowed us to have designers with different skills and different priorities; having several profiles of users has allowed us to collect representative needs of several kinds of users.

Even if our study provides empirical data about the needs elaboration process and suggests some conditions to be taken into account for succeeding the implementation of this process, it is necessary to conduct two complementary researches. First, our study considers all needs but we have seen that several categories of needs exist. Thus, conducting a further study, according to these different categories of needs, would lead us to study and to investigate the association between these different categories, the user's profiles and the design phases. Second, in our study, users cannot themselves program through co-creation tools adapted for non-experts in design (i.e., environments or languages understandable by users) because developing a VR-based software implies knowledge of high-level programming. These "end-user programming" approaches allow the design of artefacts perfectly suited to users. From the ergonomics perspective, a study aimed at analyzing and characterizing the processes of needs elaboration in these approaches where users and designers develop together could be interesting and original.

\section{Acknowledgements}

Special thanks to "Laval Agglomération" and the "Conseil Général de la Mayenne" for their support, to the industrial partners who contributed to this field study (Meubles Gautier, Groupe Dorel, Angebault), and to the IFTH (French Institute for Textiles and Clothing), sponsors of the project.

\section{References}

[1] A. Wilson, M. Bekker, H. Johnson, P. Johnson, Costs and benefits of user involvement in design: practitioners' views, in: HCI, Springer Verlag, London, 1996, pp. 221-240.

[2] F. Darses, F. Reuzeau, Chapitre 24: Participation des utilisateurs à la conception des systèmes et dispositifs de travail (User participation in the design of work systems and devices - translated by authors), in: P. Falzon (Ed.), Ergonomie, PUF, 2004.

[3] J.J. Baroudi, M.H. Olson, B. Ives, An empirical study of the impact of user involvement on system usage and information satisfaction, Commun. ACM 29 (1986) 232-238.

[4] P.D. Chatzoglou, L.A. Macaulay, Requirements capture and analysis: a survey of current practice, Requir. Eng. 1 (1996) 75-87.

[5] L. Damodaran, User involvement in the systems design process-a practical guide for users, Behav. Inf. Technol. 15 (1996) 363-377.

[6] S.T. Foster, C.R. Franz, User involvement during information systems development: a comparison of analyst and user perceptions of system acceptance, J. Eng. Tech. Manage. 16 (1999) 329-348.

[7] S. Kujala, User involvement: a review of the benefits and challenges, Behav. Inf. Technol. 22 (2003) 1-16.

[8] J. Nelson, S. Buisine, A. Aoussat, A methodological proposal to assist prospective ergonomics in projects of innovative design, Le Travail Humain 75 (2012) 279-305

[9] F. Flores, M. Graves, B. Hartfield, T. Winograd, Computer systems and the design of organizational interaction, ACM Trans. Inf. Syst. 6 (1988) 153-172.

[10] A. Folstad, O.-W. Rahlff, Challenges in conducting user-centered evaluations of mobile services, in: Human-Computer Interaction International Conference, Las Vegas, USA; 2005.

[11] M. Anastassova, User-needs analysis in early design of emerging technologies: the case of augmented reality of automotive maintenance technicians' training (in French), PhD Thesis, Psychologie - Ergonomie cognitive, Paris 5, Paris, 2006.

[12] M. Anastassova, J.-M. Burkhardt, User-needs analysis for home applications and emerging technologies: some methodological aspects, in: INTERACT'07, Workshop 'Are New Methods Needed in User-Centered System Design?', Rio de Janeiro, 2007.

[13] J.-C. Sperandio, Critères ergonomiques de l'assistance technologique aux opérateurs (Ergonomic criteria of technological assistance to operators translated by authors), in: JIM'2001: Interaction Homme - Machine \& Assistance, Metz, France, 2001.

[14] P. Béguin, Innovation et cadre sociocognitif des interactions concepteursopérateurs: une approche développementale (The role of innovation and sociocognitive context in worker-designer interactions: a developmental approach), Le Travail Humain 70 (2007) 369-390.

[15] G. Bourmaud, Du développement des instruments à la conception de systèmes techniques (From the development tools to the design of technical systems translated by authors), in: Ergo IA, Bidart/Biarritz, 2008.

[16] E. Brangier, J.-C. Simon, L'innovation par l'analyse des performances humaines: application de l'ergonomie à la conception de produits cosmétiques (Innovation through the analysis of human performance: application of ergonomics in the design of cosmetics - translated by authors), in: E. Brangier, C. Kolski, J.-R. Ruault (Eds.), Ergo'IA, 2006.

[17] J. Caelen, La plate-forme MultiCom, pour inventer les usages des objets communicants du futur ((Platform Multicom to invent uses of communicating objects of the future - translated by authors), in: PaPyrus, Le magazine de l'université Joseph Fourier, 2004.

[18] P. Rabardel, Les hommes et les technologies. Approach Cognitive des instruments contemporains (Human and technologies. Cognitive approach to contemporary instruments - translated by authors), Armand Colin, Paris, 1995.

[19] P. Rabardel, P. Beguin, Instrument mediated activity: from subject development to anthropocentric design, Theoret. Iss. Ergon. Sci. 6 (2005) 429-461.

[20] S. Robertson, Requirements trawling: techniques for discovering requirements, Int. J. Hum. Comput. Stud. 55 (2001) 405-421.

[21] F. Darses, La conception participative: vers une théorie de la conception centrée sur l'établissement d'une intelligibilité mutuelle (Participatory design: towards a theory of design centered on the development of mutual intelligibility - translated by authors), in: J.C.e.P. Mallein (Ed.), Le consommateur au coeur de l'innovation: la conception participative, Editions du CNRS, 2004, pp. 25-41.

[22] J.M.C. Bastien, D. Scapin, La conception de logiciels interactifs centrée sur l'utilisateur: étapes et méthodes (The user-centered design of interactive 
software: steps and methods - translated by authors), in: P. Falzon (Ed.), Ergonomie, PUF, Paris, 2004.

[23] S. Fleury, E. Jamet, E. Loup-Escande, A. Ghorbel, A. Lemaître, E. Anquetil, Towards some specifications for an automatic recognition software: an example of an user-centred design, J. Softw. Eng. Appl. 6 (2013) 1-4.

[24] P. Ehn, Scandinavian design: on participation and skill, in: Schuler \& Namioka (Eds.), Participatory Design: Principles and Practices, Lawrence Erlbaum Associates, Hillsdale, New Jersey, 1993.

[25] F. Kensing, J. Blomberg, Participatory design: issues and concerns, J. Comput. Supp. Cooperat. Work 7 (1998) 167-185.

[26] E. Von Hippel, Democratizing Innovation, MIT Press, 2005.

[27] Y. Reich, S.L. Konda, I.A. Monarch, S.N. Levy, E. Subrahmanian, Varieties and issues of participation and design, Des. Stud. 17 (1996) 165-180.

[28] J. Caelen, Participatory design by "moments": a collaborative management (in French), Le travail humain 72 (2009) 79-103.

[29] M.J. Muller, J.H. Haslwanter, T. Dayton, Parcipatory practices in the software lifecycle, in: L.P. Helander (Ed.), Handbook of Human Computer Interaction, Elsevier Science, Amsterdam, 1997, pp. 255-297.

[30] M. Wolff, D. Corroyer, L'analyse statistique des données en psychologie (Statistical data analysis in psychology - translated by authors), Armand Colin, Paris, 2004.

[31] Z Zhao, N. Laga, N. Crespi, The incoming trends of end-user driven service creation digital business, Lect. Notes Inst. Comput. Sci. Social Inf. Telecommun. Eng. 21 (2010) 98-108.

[32] J. Wong, J.I. Hong, Making mashups with marmite: towards end-user programming for the web, in: $\mathrm{CHI}$ '07 Proceedings of the SIGCHI Conference on Human Factors in Computing Systems, 2007, pp. 1435-1444.

[33] M.F. Costabile, P. Mussio, L. Parasiliti Provenza, A. Piccinno, Supporting end users to be co-designers of their tools, end-user development, Lect. Notes Comput. Sci. 5435 (2009) 70-85.

[34] S. Pilemalm, P.-O. Lindell, N. Hallberg, H. Eriksson, Integrating the Rational Unified Process and participatory design for development of socio-technical systems: a user participative approach, Des. Stud. 28 (2007) 263-288.

[35] F. Barcellini, F. Détienne, J.-M. Burkhardt, Users and developers mediation in an Open Source Software Community: boundary spanning through cross participation in online discussions, Int. J. Hum Comput Stud. 66 (2008) 558-570.

[36] E. Loup-Escande, O. Christmann, Designing a Virtual Reality software: what is the real contribution of end-users to the requirements prioritization?, in: J. Filipe, L.A. Maciaszek (Eds.), Evaluation of Novel Approaches to Software Engineering (Communications in Computer and Information Science Series), Springer-Verlag, Berlin Heidelberg, 2013, pp. 1-15.

[37] E. Loup-Escande, J.-M. Burkhardt, S. Richir, Anticiper et évaluer l'utilité dans la conception ergonomique des technologies émergentes: une revue (Anticipating and evaluating the usefulness of emerging technologies in ergonomic design: a review of usefulness in design), Le Travail Humain 76 (2013) 25-55

[38] O. Plos, S. Buisine, A. Aoussat, C. Dumas, Analysis and translation of user needs for assistive technology design, in: ICED'07 International Conference on Engineering Design, 2007.

[39] A. Blandford, T.R.G. Green, D. Furniss, S. Makri, Evaluating system utility and conceptual fit using CASSM, Int. J. Hum. Comput. Stud. 66 (2008) 1-26.

[40] V. Folcher, Appropriating artifacts as instruments: when design-for-use meets design-in-use, Interact. Comput. 15 (2003) 647-663.

[41] P. Béguin, Design as a mutual learning process between users and designers, Interact. Comput. 15 (2003) 709-730.

[42] J. Rasmussen, Information Processing and Human-Machine Interaction: An Approach to Cognitive Engineering, Elsevier Science Inc., 1986.

[43] J. Rasmussen, Skills, rules, and knowledge; signals, signs, and symbols, and other distinctions in human performance models, in: System Design for Human Interaction, IEEE Press, 1987, pp. 291-300.

[44] E. Loup-Escande, J.-M. Burkhardt, S. Richir, L'élaboration de spécifications par trois profils de concepteurs (ingénieurs, designers, ergonomes): une étude expérimentale elaboration of specifications by three profiles of designers (engineers, designers, ergonomists): an experimental study), in: Epique, Metz, France, 2011

[45] ISO 9241-210:2010, Ergonomics of human-system interaction Part 210: Human-centred design for interactive systems, 2010.

[46] M. Maguire, N. Bevan, User requirements analysis: a review of supporting methods, in: Proceedings of the IFIP 17th World Computer Congress - TC13 Stream on Usability: Gaining a Competitive Edge, Kluwer, B.V., 2002.

[47] L.A. Macaulay, Requirements Engineering, Springer-Verlag, Berlin, Heidelberg, New York, 1996, p. 202

[48] B. Alenljung, Decision-Making in the Requirements Engineering Process: A Human-centred Approach, Department of Computer and Information Science, Institute of Technology at Linköping University, Linköping, 2005, p. 111.
[49] B. Alenljung, A. Persson, Portraying the Practice of Decision-making in Requirements Engineering - A Case of Large Scale Bespoke Development, Requirements Engineering, 2008.

[50] A. Aurum, C. Wohlin, The fundamental nature of requirements engineering activities as a decision-making process, Inf. Softw. Technol. 45 (2003) 945-954.

[51] E. Loup-Escande, O. Christmann, Requirements Prioritization by End-users and Consequences on Design of a Virtual Reality Software: An Exploratory Study, ENASE, Angers, France, 2013.

[52] M. Anastassova, J.-M. Burkhardt, C. Mégard, A. Leservo, User-centred design of mixed reality for vehicle maintenance training: an empirical comparison of two techniques for user needs analysis, in: Proceedings of $\mathrm{HCI}$ International, Las Vegas, July 22-27, 2005.

[53] M. Anastassova, C. Mégard, J.-M. Burkhardt, Prototype evaluation and userneeds analysis in the early design of emerging technologies, Hum.-Comput., Interact. Interact. Des. Usab. 4550 (2007) 383-392.

[54] J. Nelson, S. Buisine, A. Aoussat, Assisting designers in the anticipation of future product use, Asian Int. J. Sci. Technol. Prod. Manuf. Eng. 2 (2009) 24-39.

[55] J. Nelson, S. Buisine, A. Aoussat, C. Gazo, Generating prospective scenarios of use in innovation projects, Le Travail Humain 77 (2014) 21-38.

[56] P. D’Astous, F. Détienne, W. Visser, P.N. Robillard, Changing our view on design evaluation meetings methodology: a study of software technical evaluation meetings, Des. Stud. 25 (2004) 625-655.

[57] F. Darses, M. Wolff, How do designers represent to themselves the users' needs?, Appl Ergon. 37 (2006) 757-764

[58] J. Karlsson, C. Wohlin, B. Regnell, An evaluation of methods for prioritizing software requirements, Inf. Softw. Technol. 39 (1998) 939-947.

[59] O. Ma, The Effectiveness of Requirements Prioritization Techniques for a Medium to Large Number of Requirements: A Systematic Literature Review, Auckland University of Technology as a Part of the Requirements for the Degree of Master of Computer and Information Science, 2009.

[60] D.M. Berry, K. Daudjee, J. Dong, I. Fainchtein, M.A. Nelson, T. Nelson, L. Ou, User's manual as a requirements specification: case studies, Require. Eng. 9 (2004) 67-82.

[61] E. Loup-Escande, J.-M. Burkhardt, H. Christofol, S. Richir, 3D Child Software: a decision-making help tool in innovative product design, J. Decision Syst. 19 (2010) 9-31.

[62] S. Richir, P. Fuchs, La méthode $\mathrm{I}^{2} I$ : Interaction et Immersion pour l'Innovation (The $\mathrm{I}^{2} \mathrm{I}$ method: Interaction and Immersion for Innovation), in: Techniques de l'ingénieur, 2006, p. 1-9.

[63] P. Fuchs, G. Moreau, L'interfaçage, l'immersion et l'interaction en environnement virtuel (Interfacing, immersion and interaction in virtual environments - translated by authors), in: Le traité de la réalité virtuelle, Presses de l'École des Mines, Paris, 2006.

[64] F. Darses, D. Brissaud, B. Cahour, J.-B. Delabie, O. Garro, F. Lorant, D. Mathot, V. Pêcheux, O. Poveda, Intégration des points de vue en conception (Integration of points of view in design - translated by authors), in: F. Darses (Ed.), Rapport final de Recherche du projet INTEGRE, CNAM, Paris, 2002, p. 170.

[65] W. Visser, The Cognitive Artefacts of Designing, Lawrence Erlbaum Associates, 2006.

[66] G.L. Urban, J.R. Hauser, Design and Marketing of New Products, Prentice Hall, 1980.

[67] T.K. Ulrich, S.D. Eppinger, Product Design and Development, third ed., Mac Graw Hill, 2003

[68] A. Delamarre, Contribution du "produit concept" à l'organisation des phases préliminaires du processus de conception en PME (Contribution of the "product concept" to the organization of preliminary stages of the design process in SMEs - translated by authors), in: Thèse de doctorat, Science de l'ingénieur, Université d'Angers, Angers, 2006, pp. 132.

[69] J.-M. Burkhardt, J.-C. Sperandio, Ergonomie et conception informatique (Ergonomics and computer design), in: P. Falzon (Ed.), Ergonomie, PUF, Paris, 2004.

[70] D. Corroyer, H. Rouanet, On the importance of effect size and indicators of effect size in the statistical analysis of data, L'année Psychologique 94 (1994) 607-624.

[71] H. Cramer, Mathematical Methods of Statistics, Princeton University Press, 1999.

[72] J.-M. Bernard, Analysis of local or asymmetric dependencies in contingency tables using the imprecise Dirichlet model, in: Paper Presented at the $3 \mathrm{~d}$ International Symposium on Imprecise Probabilities and Their Applications ISIPTA'03, Lugano, Switzerland, 2003.

[73] F. Barcellini, Artefact and Community Design: Dynamic of an Open and Continuous Design Process in an Open Source Software Community (in French), PhD Thesis, Ergonomie, CNAM, Paris, 2008.

[74] J. Kjeldskov, Human-Computer Interaction Design for Emerging Technologies: Virtual Reality, Augmented Reality and Mobile Computer Systems, Thesis, Aalborg University, Aalborg, 2003. 